\title{
Effect of Local Binary Mixtures of Coarse Aggregates on the Compressive Properties of Concrete
}

\author{
Eze O. K. and Nwankwo E.* \\ Department of Civil Engineering, Faculty of Engineering, University of Benin, Benin City, Edo State, Nigeria \\ Corresponding Author: *nwankwoebuka@ yahoo.co.uk
}

https://doi.org/10.36263/nijest.2020.01.0172

\begin{abstract}
Aggregates, though considered inert, are the primary components that define concrete's thermal and elastic properties. It has been shown that factors such as maximum aggregate size, grading, shape, strength, water absorption capacity of coarse aggregates affect the properties of concrete. However, improper grading of coarse aggregate could have adverse effect on the amount of cement and water requirement for concrete production. Thus, impacting on the workability, pump-ability and durability of concrete. By maintaining a slump of $50 \mathrm{~mm}$, the effect of varying sizes of coarse aggregates $-10 \mathrm{~mm}, 14 \mathrm{~mm}, 20 \mathrm{~mm}$, and combination of these sizes - on the mechanical properties of concrete was obtained. Aggregates, which were used in this work, were sourced from quarries located in Auchi area of Edo State and had impact values between 16\% and 28\%. It was observed that the higher the coarse aggregate sizes the lower the water - cement $(w / c)$ ratio required to obtain adequate workability. Also, the compressive strength of concrete was observed to be a function of the size of the coarse aggregates used in the concrete mix. It was observed that concrete made with equal proportions of $10 \mathrm{~mm}$ and $14 \mathrm{~mm}$ coarse aggregate had lower strengths compared to concrete made with $14 \mathrm{~mm}$ and $20 \mathrm{~mm}$ aggregates. This implies that combination of large sizes of aggregates produced stronger concrete when compared to combinations of smaller sizes of aggregates. It was also observed that density of concrete increased with increasing size of aggregates.
\end{abstract}

Keywords: Aggregate, Grading, Regression, Compressive strength

\subsection{Introduction}

Aggregates constitute basic component of concrete usually constituting about 75 percent of the volume. The volume occupied by aggregates in concrete underscores its importance. The grading of fine aggregates (size less than $4.7 \mathrm{~mm}$ ) and coarse aggregates (size greater than $4.7 \mathrm{~mm}$ ) are generally required in concrete production.

Experiments have shown that the size, type, shape and grading of aggregates have significant impact on the mechanical properties of concrete (Molugaram et al., 2014; Vilane and Sabelo, 2016; Czuryszkiewicz, 1973; Ogundipe et al., 2018; Kalra and Mehmood, 2018; Tsiskreli and Dzhavakhidze, 1970). Many researchers have also investigated the effect of type and source of aggregate on the mechanical properties of concrete (Al-Oraimi et al., 2006; Ahmad and Alghamdi, 2012). Wu et al. (2019) investigated the effect of using crushed quartzite, crushed granite, limestone, and marble as coarse aggregate on the on the mechanical properties of high-performance concrete. They observed that the strength, stiffness, and fracture energy of concrete for a given water/cement ratio depend on the type of aggregate.

Bilal El-Ariss (2006) investigated the influences of the water/cement (W/C) ratio, coarse and fine aggregates (FA), CA/total aggregate (CA/TA) ratio, TA/C ratio, and curing methods (air curing, oven curing, and water curing) on the compressive strength of concrete. This work went on to develop mathematical formula for calculating concrete strength as a function of CA quantity that ranges from the standard quantity to null, and another formula was developed for the quantity of FA as a function of compressive strength. In-depth analyses have been conducted by researchers to establish the effect 
of aggregates on concrete. By using advanced image analysis technique, it was observed that aggregates with limestone geology and shape characteristic (i.e. with higher circularity and aspect ratio) performed well in the production of higher strength concrete in comparison to other aggregates (Sadiq et al., 2019).

It has been established that aggregates have significant effect on other mechanical properties of concrete, apart from basic properties related to compressive strength. The effect of aggregate size on fracture energy, tensile strength and elasticity modulus of concrete has also been investigated (Rocco and Elices, 2009; Arslan and Kamas, 2017). Rocco and Elices (2009) found that concrete made with crushed aggregate shows slightly higher fracture energy than concrete made with spherical ones. Their work showed that fracture energy increases with aggregate size for both types of aggregates. Also, it has also been shown that in a concrete beam made with fine fractions of coarse aggregate, the fracture energy, final displacement at the mid-span and splitting tensile strength are higher than those of the concrete with coarse fraction (Akcay and Tasdemir, 2006).

It has also been observed that grading and source of granite have significant effect on the strength of concrete. Okonkwo and Arinze (2015) observed that concrete with coarse aggregate sizes of $20 \mathrm{~mm}$ exhibited higher compressive strength than concrete made aggregates of lower sizes. However, this work does not show the effect of combining various sizes of aggregate on the compressive of concrete.

\subsection{Methodology}

Ordinary Portland Grade 30 cement (which confirms to ASTM 150 standards) was used in this research. Accompanying coarse and fine aggregates were obtained from Okhuahia in Edo State and Auchi in Edo State, respectively. Sieve analysis -using BS 410:1986- was conducted for aggregates obtained as shown in Figures 1 and 2. From the aggregates obtained for this study, uniform grade sizes of $10 \mathrm{~mm}, 14 \mathrm{~mm}$ and $20 \mathrm{~mm}$ were obtained.

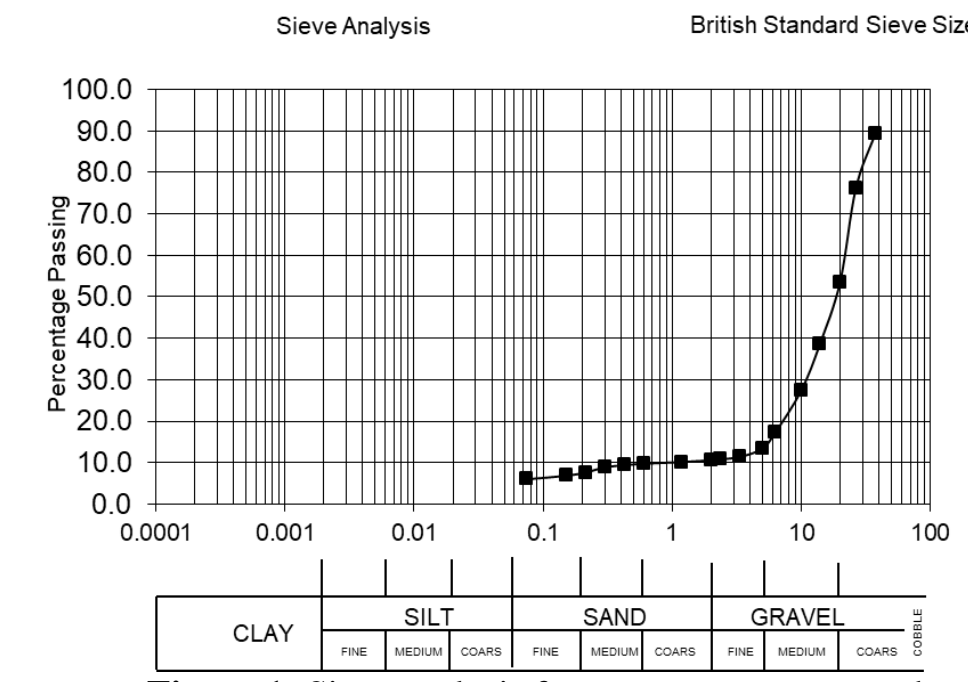

Figure 1: Sieve analysis for coarse aggregate used

The mix design method adopted is the British method of mix design restricted to designing concrete mixes to meet workability, compressive strength and durability requirements using Ordinary Portland cements complying with BS 12 or BS 4027 and natural aggregates complying with BS 882. Table 1 shows the mix ratios used in batching a cubic meter of concrete. The mix ration adopted in Table 1 is equivalent to the mix ratio obtained for Grade 40 concrete in (Hamad and Dawi, 2017). 


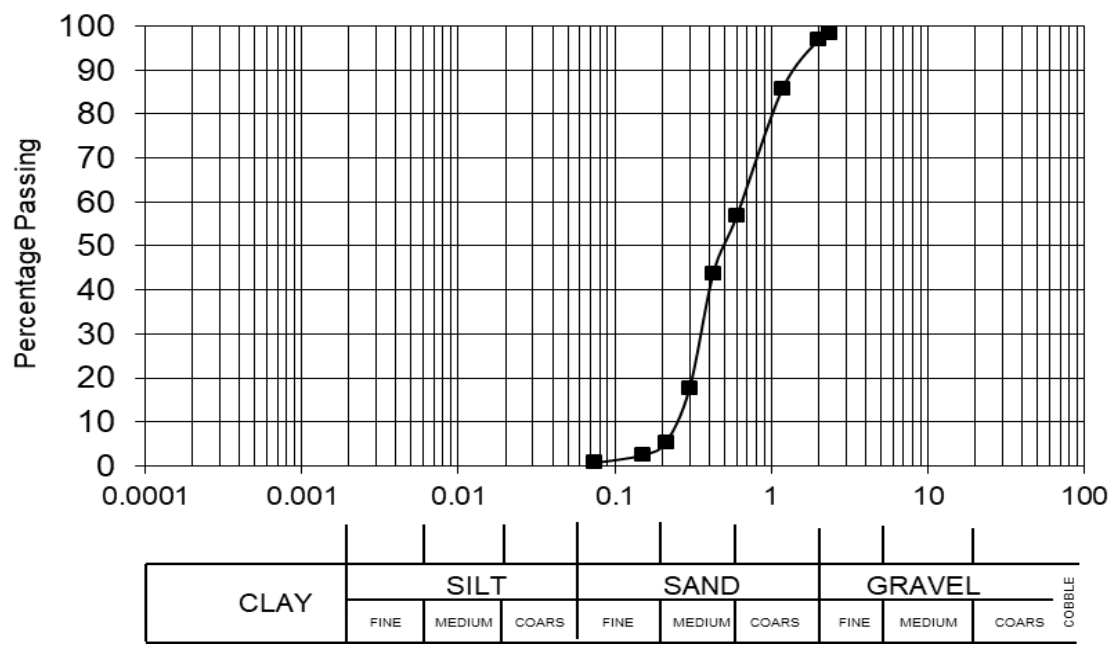

Figure 2: Sieve analysis for fine aggregate used

Table 1: Mix design used for research

\begin{tabular}{ccc}
\hline Cement $\left(\mathrm{kg} / \mathrm{m}^{3}\right)$ & Fine aggregate $\left(\mathrm{kg} / \mathrm{m}^{3}\right)$ & Coarse aggregate $\left(\mathrm{kg} / \mathrm{m}^{3}\right)$ \\
\hline 420 & 708 & 1062 \\
\hline
\end{tabular}

Slump test was conducted on samples in accordance with BS EN 12350-2:2009. The mould used for the slump test was a conical frustum, $300 \mathrm{~mm}$ high. The mould was placed on a smooth surface with the smaller opening at the top and filled with concrete in three layers. Each layer was tamped 25 times with a standard $16 \mathrm{~mm}$ diameter and $60 \mathrm{~cm}$ long steel tamping rod, rounded at the end and the top surface of the final layer was smoothened with a trowel. The mould was firmly held against its base during the entire operation. Immediately after filling was done, the cone was slowly lifted and the unsupported concrete was slumped, hence, the name slump test. The decrease in height of the highest part of the slumped concrete is called the slump and is measured to the nearest $5 \mathrm{~mm}$. In practice, concrete with slump between $50-90 \mathrm{~mm}$ are generally regarded as concrete with medium workability. In this work, a fixed workability of $50 \mathrm{~mm}$ was used for all concretes.

The compressive strength of cast concrete cubes, after curing, was obtained by crushing after 7, 21 and 28 days, respectively. Curing was achieved by placing cast concrete cubes in a pure water curing bath. Cubes were removed from curing bath and allowed to dry, weighed and placed in the compression machine for crushing according to specification of BS 1881 part 1, 1970. The crushing load was applied at a rate of $15 \mathrm{~N} / \mathrm{mm}^{2}$ per minute. A total of 42 cubes were tested for each concrete made with the following aggregate sizes and combinations: $10 \mathrm{~mm}, 14 \mathrm{~mm}, 20 \mathrm{~mm}, 10 / 14 \mathrm{~mm}, 14 / 20$ $\mathrm{mm}, 10 / 20 \mathrm{~mm}$ and 10/14/20 $\mathrm{mm}$.

\subsection{Results and Discussion}

The specific gravity of coarse aggregates used ranged between 2.72 and 2.86 . The average aggregate impact value of coarse aggregate used is $21.84 \%$. Average values of compressive strengths from samples were used to establish points on Figures 3 to 8. The average values used to establish points were between $\pm 3 \%$ of the largest and minimum values obtained for each point.

Table 2 shows the different water cement ratios required to achieve a slump of $50 \mathrm{~mm}$ for the various concrete mixes with varying aggregates sizes. It was observed that workability is a function of coarse aggregate size in a mix. It was observed that the higher the coarse aggregate sizes the lower the water - cement ratio required obtain adequate workability. This is because the water content required to produce a workable concrete is less for concrete made with large coarse aggregate size than the water content to produce a concrete of same workability with smaller size coarse aggregate.

Figure 3 shows that the compressive strength of concretes - with the same slump -- made with varying sizes of aggregate. As shown in Figure 3, compressive strength increases as the size of aggregates increased. 
Table 2: Water cement ratio for different aggregates

\begin{tabular}{ccc}
\hline Aggregate sizes in $\mathrm{mm}$ & Water Content $\left(\mathrm{kg} / \mathrm{m}^{3}\right)$ & w/c ratio \\
\hline 10 & 210 & 0.5 \\
14 & 195 & 0.48 \\
20 & 180 & 0.44 \\
$10 / 14$ & 195 & 0.48 \\
$10 / 20$ & 185 & 0.45 \\
$14 / 20$ & 185 & 0.45 \\
$10 / 14 / 20$ & 195 & 0.48 \\
\hline
\end{tabular}

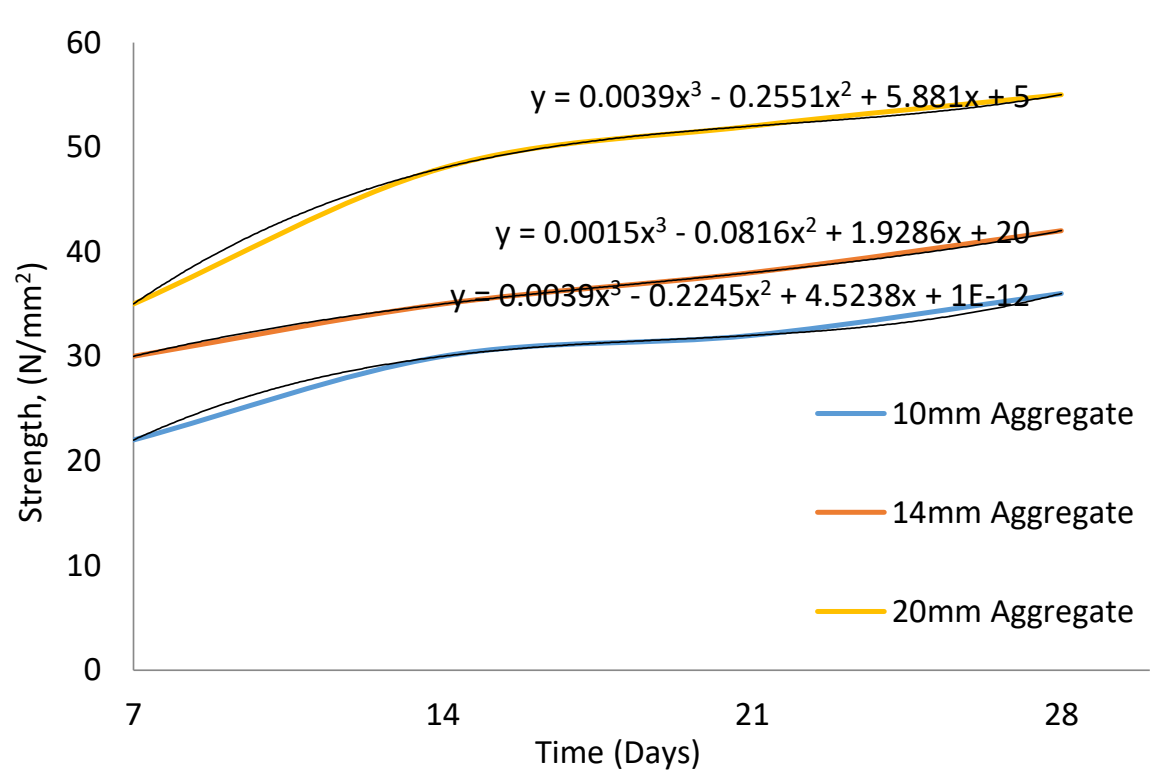

Figure 3: Compressive strength test result of made with same size coarse aggregate grade

Figure 4 shows the effect of combining other sizes of aggregates with $14 \mathrm{~mm}$ and aggregates. It is observed that combining $14 \mathrm{~mm}$ and $20 \mathrm{~mm}$ sized aggregates, in equal weights, produced concrete with higher strengths when compared combinations with $10 \mathrm{~mm}$ and the $10 \mathrm{~mm} / 14 \mathrm{~mm} / 20 \mathrm{~mm}$ combination.

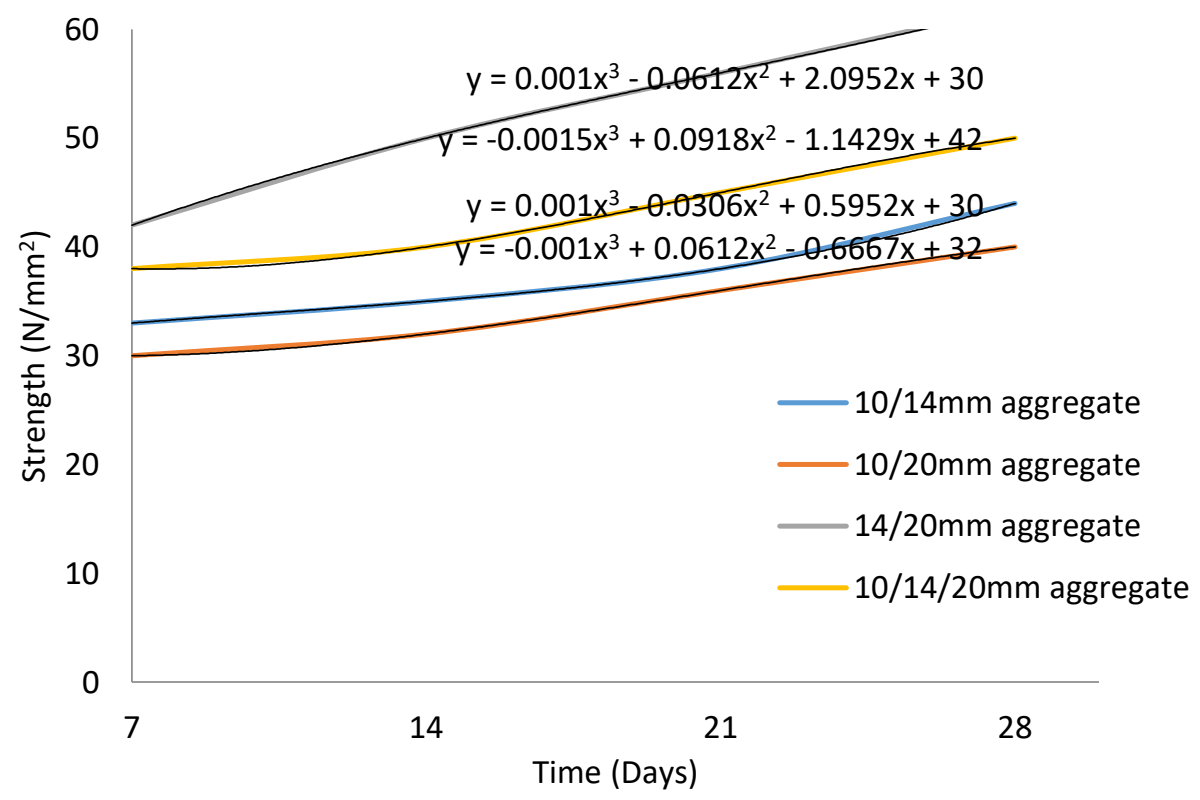

Figure 4: Trendlines for compressive strength test result of concrete made with different sizes of aggregate and grading 
Figure 5 shows the effect of combining other sizes of aggregates with $10 \mathrm{~mm}$ and aggregates. It is observed that combining $10 \mathrm{~mm}, 14 \mathrm{~mm}$ and $20 \mathrm{~mm}$ sized aggregates, in equal weights, produced concrete with higher strengths when compared to individual combinations with $14 \mathrm{~mm}$ and $20 \mathrm{~mm}$ aggregates.

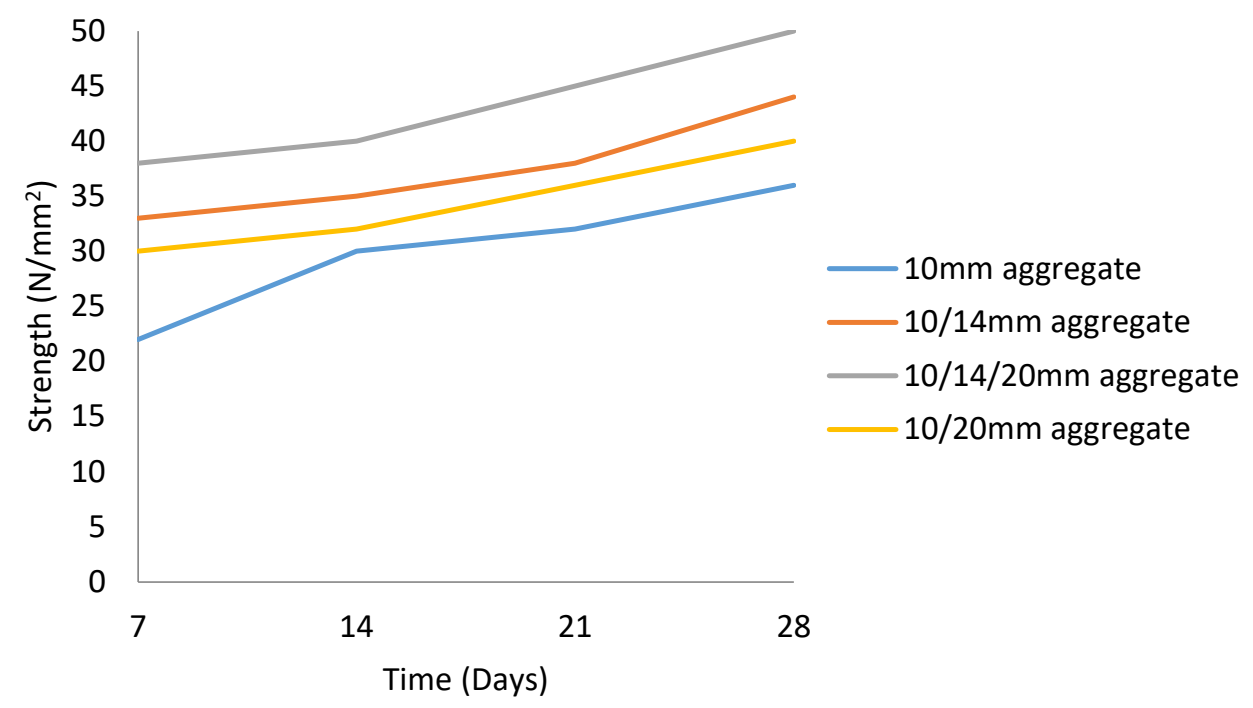

Figure 5: Comparison between concrete made with $10 \mathrm{~mm}$ aggregates and varying proportions of higher sizes

Figure 6 and 7 show that combining $14 \mathrm{~mm}$ and $20 \mathrm{~mm}$ sized aggregates, in equal weights, produced concrete with higher strengths when compared $10 \mathrm{~mm} / 14 \mathrm{~mm}$ and $10 \mathrm{~mm} / 14 \mathrm{~mm} / 20 \mathrm{~mm}$ combinations aggregates.

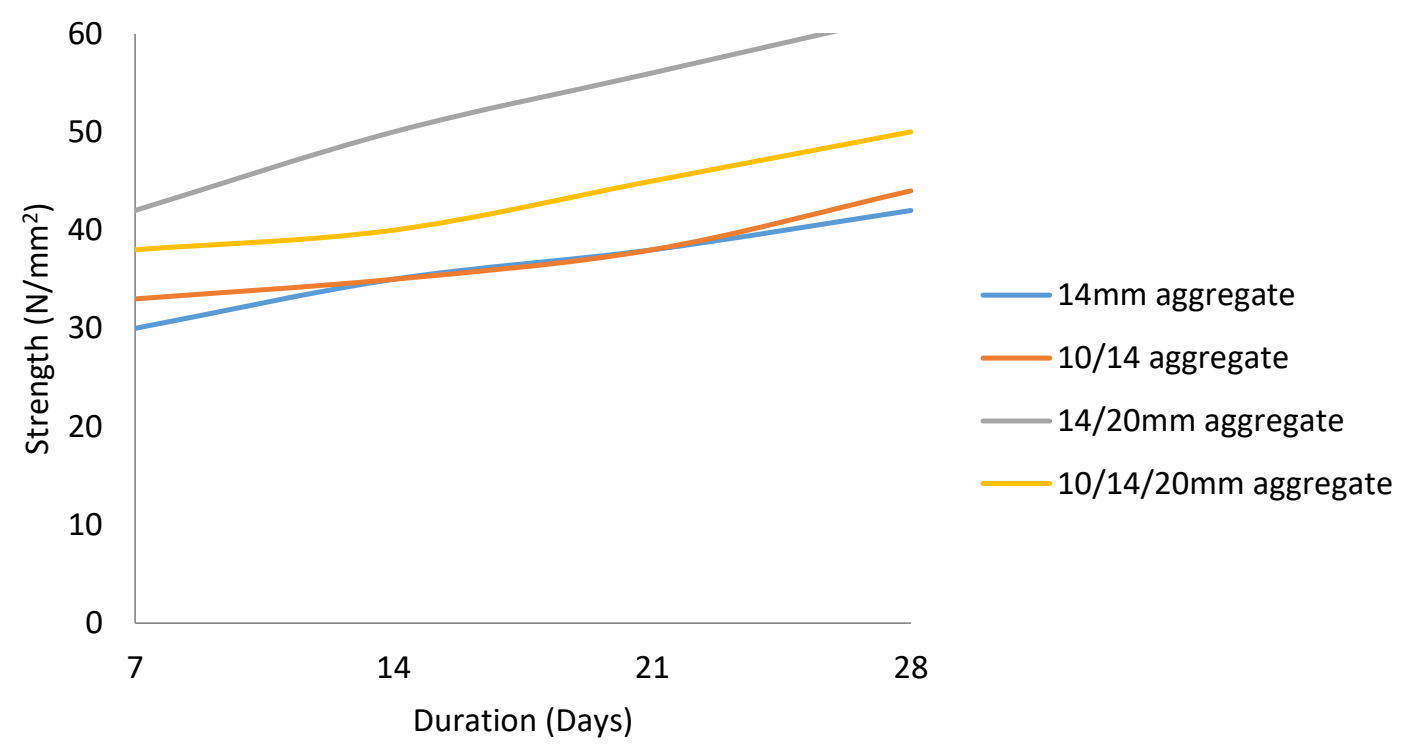

Figure 6: Comparison between concrete made with $14 \mathrm{~mm}$ aggregates and varying proportions of other sizes 


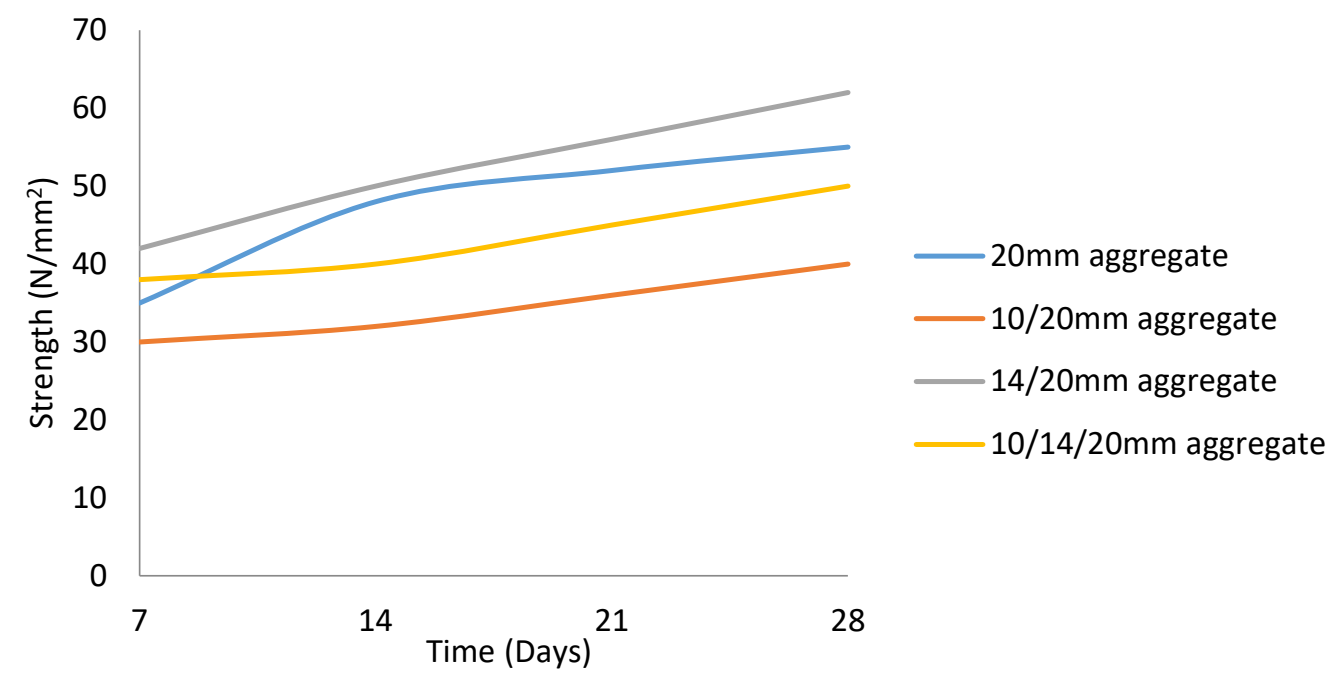

Figure 7: Comparison between concrete made with $14 \mathrm{~mm}$ aggregates and varying proportions of other sizes

Figure 8 shows the density of concrete increases as the sizes of aggregates used increases.

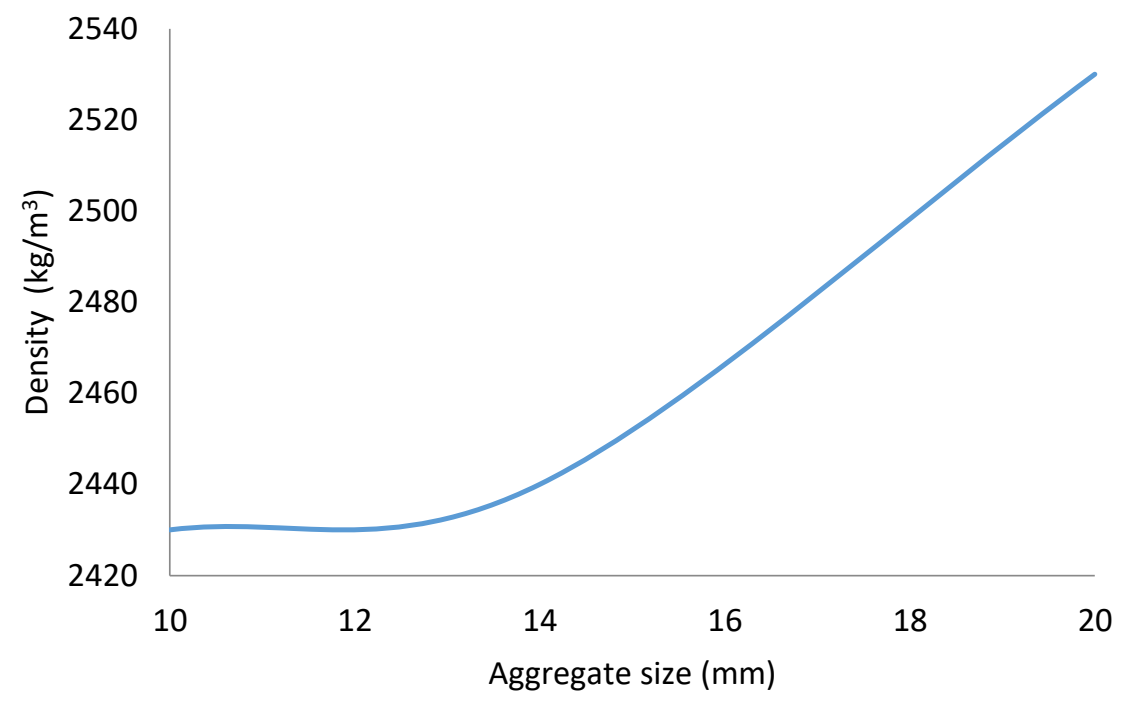

Figure 8: Varying density of concrete prepared with different aggregate

\subsection{Conclusions}

$10 \mathrm{~mm}, 14 \mathrm{~mm}$ and $20 \mathrm{~mm}$ aggregates are the prevalent coarse aggregate used in local construction in Nigeria. Preparation of concrete for local construction usually involves proportioning these common sizes to produce concrete. Thus, it is imperative to understand how the combination of these aggregates impact on the compressive strength of concrete. It was observed that the higher the coarse aggregate sizes the lower the water - cement ratio required to obtain adequate workability. This is traced to surface area of the coarse aggregate. The smaller the aggregate size in a grade the greater the surface area needed to be wetted which is a function of the water requirement. It is important to note that the water absorption rates of the aggregates were not investigated in this work. However, all aggregates used in this work were sourced from the same source.

Experimental results obtained from using these sizes of aggregates and show that:

1. The density of concrete produced increases as the sizes of aggregates increased. Concrete made with single aggregates sizes of $20 \mathrm{~mm}$ showed significant increase in density when compared to concrete made with less sizes of single aggregates

2. Compressive strength increases as the size of aggregates increased. 
3. Concrete with graded aggregates having aggregate sizes of $20 \mathrm{~mm}$ showed improved compressive strengths when compared to concretes made with graded aggregates with lower sizes

Concrete made with graded aggregates show higher strengths when compared to concrete made with single sized aggregate. This can be explained by the fact that well graded aggregates produce well compacted and denser concrete by ensuring that voids within the concrete are at a minimum.

\section{References}

Akcay, B. and Tasdemir, M. (2006). Effects of Lightweight Aggregates on Autogenous Deformation in Concrete. Measuring, Monitoring and Modeling Concrete Properties, pp. 163-170. https://doi.org/10.1007/978-1-4020-5104-3 20

Ahmad, S. and Alghamdi, S. A. (2012). A Study on Effect of Coarse Aggregate Type on Concrete Performance. Arab J Sci Eng, 37, pp. 1777-1786. https://doi.org/10.1007/s13369-012-0282-6

Al-Oraimi, S. K., Taha, R. and Hassan, H. F. (2006). The effect of the mineralogy of coarse aggregate on the mechanical properties of high-strength concrete. Construction and Building Materials, 20(7), pp. 499-503.

Arslan, B. and Kamas, T. (2017). Investigation of aggregate size effects on the compressive behavior of concrete by electromechanical and mechanical impedance spectroscopy. Procedia Structural Integrity, 5, pp. 171-178.

Bilal El-Ariss (2006). Effect of reducing coarse aggregates on concrete strength. Construction and Building Materials, 20(3), pp. 149-157.

Czuryszkiewicz, Andrzej (1973). The effect of aggregate shape upon the strength of structural lightweight-aggregate concrete. Magazine of Concrete Research, 25(83), pp. 81-86.

BS EN 12350-2:2009: Testing Fresh Concrete: The Slump Test

BS 1881-1:1970: Methods of testing concrete. Method of mixing and sampling fresh concrete in the laboratory

Hamad, B. S. and Dawi, A. H. (2017). Sustainable normal and high strength recycled aggregate concretes using crushed tested cylinders as coarse aggregates. Case Studies in Concrete materials, (7), pp. 228-239.

Kalra, M. and Mehmood, G. (2018). A review paper on the effect of different types of coarse aggregate on concrete. Materials Science and Engineering, 431, pp. 1-7.

Molugaram, K., Shanker, J. S. and Ramesh, A. (2014). A Study on Influence of Shape of Aggregate on Strength and Quality of Concrete for Buildings and Pavements. Advanced Materials Research, 941-944, pp. 776-779.

Sadiq, A., Raheel, S., Syed, A., Siddiq, U., Anwar, M., Saeed, M., et al. (2019). Analysis of aggregate shape and texture by advance image analysis technique and its impact on strength of concrete. Proceedings of the International Civil Engineering \& Architecture Conference, 17 - 20 April, Trabzon, Turkey, pp. 2164- 2172

Ogundipe, O. M., Olanike, A. O., Nnochiri, E. S. and Ale, P. O. (2018). Effects of Coarse Aggregate Size on the Compressive Strength of Concrete, 4(4), pp. 836 - 841

Okonkwo, V. O. and Arinze, E. E. (2015). Effects of Aggregate Gradation on the Properties of Concrete made from granite chippings. International Journal of Advancements in Research \& Technology, 4(12), pp. 17 -20. 
Rocco, C. and Elices, M. (2019). Effect of aggregate shape on the mechanical properties of a simple concrete. Engineering Fracture Mechanics, 76(2), pp. 286-298.

Tsiskreli, G. D. and Dzhavakhidze, A. N. (1970). The effect of aggregate size on strength and deformation of concrete. Hydrotechnical Construction, 4, pp. 448-453.

Ukala, D. C. (2019). Effects of combined aggregate gradation on the compression strength and workability of Concrete using Fineness Modulus. J. Appl. Sci. Environ. Manage, 23(5), pp. 851-856

Vilane, B. R. and Sabelo, N. (2016). The effect of aggregate size on the compressive strength of concrete. Journal of Agricultural, 2(6), pp. 66-69.

Wu, K-R., Chen, B., Yao, W. and Zhang, D. (1997). Effect of coarse aggregate Type on Mechanical Properties of High-Performance Concrete. Cement and Concrete Research, 31(10), pp. 1421-1425.

Cite this article as:

Eze O. K. and Nwankwo E., 2020. Effect of Local Binary Mixtures of Coarse Aggregates on the Compressive Properties of Concrete. Nigerian Journal of Environmental Sciences and Technology, 4(1), pp. 152-159. https://doi.org/10.36263/nijest.2020.01.0172 